\title{
Development of a Behavior-Based Passenger Flow Assignment Model for Urban Rail Transit in Section Interruption Circumstance
}

\author{
Jing Teng ${ }^{1}$ - Wang-Rui Liu ${ }^{1}$
}

Received: 3 December 2014/Revised: 15 February 2015/Accepted: 19 February 2015/Published online: 9 May 2015

(C) The Author(s) 2015. This article is published with open access at Springerlink.com

\begin{abstract}
At present, the urban rail transit (URT) system has achieved network operation in many major cities of China. But, little attention has been given to the vulnerability of the URT system. The purpose of this study is to assign the passenger flow under the condition of section interruption in URT system. Two surveys (a passenger behavior survey and a stated preference survey) were conducted and a multinomial logit model was developed. The results show that although the first choice of passengers in emergency situation is to stay in URT system by a circuitous way, more than half of the respondents express interest in the temporary shuttle bus. For the temporary shuttle bus, the sensitivity analysis show that the relative speed is more important than crowding degree for passengers. The significant variables mostly fall in the personal attributes such as income, gender, age, etc. The impacts of trip feature factors are similar to the previous research in normal situations. These results provide basic support for passenger flow assignment at the shuttle bus level and reducing the risk of crowding at some special stations. Moreover, it is also good for reducing passenger delay and recovering the trip.
\end{abstract}

Keywords Urban rail transit - Section interruption . Passenger flow assignment · SP survey $\cdot$ Multinomial logit model

Wang-Rui Liu

liuwangrui@sina.com

1 Key Laboratory of Road and Traffic Engineering, Ministry Education, Tongji University, 4800 Cao'An Road, JiaDing District, Shanghai, China

Editor: Marin Marinov

\section{Introduction}

URT, with its large capacity and high reliability, is gradually developing to be the favorite traffic mode in metropolis. However, for the concentrated passenger flow, limited space, closed running, and high capacity characteristics, once an emergent event happens in URT system and operation is interrupted, will come out in a huge amount of delay and spread rapidly in network.

According to the process of emergent measures in URT system, the organization of passenger flow can be divided into two steps-evacuation and recovery. The former is at the beginning of emergent events, trying to evacuate passengers to a safe place as fast as possible; the latter is active after the evacuation step and all potential risks will be cleared. During the recovery phase, the common practice is to maintain the integrated service of OD trips, using other traffic modes, usually bus transit, to replace the interrupting section, which is the research question in this paper.

The basic need in emergency situation is to maintain the accessibility of rail lines and the integrated service of OD trips; that is to say, some indispensable measures need to be proposed on transport organization level. Passenger flow assignment under emergent condition provides essential support for emergency decision, such as adjusting train routings and departure intervals, scheduling plans of shuttle buses (i.e., the temporary shuttle buses), etc.

Quite a few studies [5-8] have focused on passenger flow assignment in URT network. User-equilibrium model and discrete choice model are the most commonly used methods in passenger flow assignment. The factors in the generalized cost function consist of rail-ride travel time and passengers' stay time at a transfer or passing station. An amplification factor is usually introduced to describe transfer time. Though some different disposal ways were 
adopted for these factors in previous papers, they were not considered from passengers' standpoint. For example, invehicle crowding degree is hardly considered in previous papers for it is hard to be measured in practice. In addition, comparing with the variable of the number of stations, most papers prefer travel time. Although travel time seems to be more accurate and objective, the variable of the number of stations has its own advantages, such as, the number of stations between the interrupting section and the origin station, the number of stations between the interrupting section and the destination station. These variables are probably more intuitive and convenient for passengers to choose the best route in emergency situations.

In recent years, some researches [9-11] pay attention to passenger flow assignment under emergent condition in URT network. Delay on passengers and the affected area are considered. The number of affected passengers is also calculated for every affected station. However, these researches are still in the theoretical stage, and many practical factors are out of consideration, which will be hard to provide enough support for the emergent decision makers.

This paper selects factors, in the utility function, from both the passenger behavior survey and previous researches. These factors are brought in the state preference (SP) survey, including the crowding degree, relative speed, the number of stations in the shortest route, etc. In the SP survey, a shuttle bus passageway replacing the interrupting section is assumed to establish an integrated URT network. Then, a discrete choice model is built and analyzed. The objective of this paper is to assign passenger flow under emergent condition and to provide support for the emergent decision makers.

The paper is organized as follows: first, previous researches on passenger flow assignment in normal and emergent situations in URT system are reviewed, followed by a detailed explanation of the methodology and data preparation, including passenger behavior survey, SP survey, and route choice model. Then, with the data collected from a passenger behavior survey and a SP survey in Shanghai URT system, the route choice model is calibrated and analyzed.

\section{Literature Review}

Several existing reports $[1,2]$ presented the importance of using the bus transit as the connecting mode when railway or metro emergent events happen. Between the URT and bus systems, the synergy of timetables was the key to realize the intermodal transportation in emergency. Shanghai subway system stipulated [3] the shuttle buses need to be deployed when the delay of the system is more than 30 min. Beijing subway system also stipulated [4] traffic control need to be implemented and the shuttle bus need to be deployed in emergency. These researches show that the bus is a crucial traffic mode in emergent event of URT system, and the passenger flow assignment is the basis of all emergent decisions.

Previous researches on passenger flow assignment in URT system can be divided into two branches: equilibrium assignment model and utility theory based non-equilibrium assignment model. The papers used travel time, mileage or travel fare in generalized cost function to analyze the passenger's route choice.

Zhu [5] used the method of successive averages to solve the stochastic user-equilibrium problem. He/she described the impact of congestion on passengers' route choices. A generalized cost function with in-vehicle congestion and an amplification factor for transfer time was set up. With the $\mathrm{K}$-th shortest path algorithm to generate the choice set, a route choice model was introduced to perform the stochastic network. Comparing with those practical methods used in China, this model computed more precisely. However, the passenger behavior was not considered. In addition, the effective paths were restricted by a constant or a parameter relating to the shortest path. As different OD pairs have their own transfer times and mileage, it is difficult to practically analyze the effective paths using this criterion. This model was inspired by the flow assignment theory for road traffic, but several features needed to be noticed when this model was applied into URT network: (i) The generalized travel cost is affected considerably by in-vehicle congestion rather than vehicle-to-vehicle congestion; (ii) The transfer time at the transfer station influences the route choices of rail passengers considerably.

Si [6] proposed a modified logit-based passenger flow assignment model, using automatic fare collection (AFC) data as basic data. This paper also adopted an amplification factor for transfer time. In addition, transfer time was considered separately. Compared with all-or-nothing assignment method, this model was more practical and reasonable, according to the Beijing AFC data. Si [7] made a survey about the passenger travel behavior in Beijing URT system. Some parameters were modified and the general framework of passenger flow assignment was presented in this paper. However, the generalized cost functions in these two researches were nearly the same to equilibrium assignment model which considered travel time, transfer time, and transfer times only. Some factors, like crowding level which can reasonably reflect travelers' behaviors, had not been included. Meanwhile, the comparison with all-ornothing assignment method seemed unpersuasive.

In recent years, a new thought was proposed with URT system's own features. Zhou [8] narrowed down the feasible paths chosen by one passenger based on the train timetable and AFC record data. Assuming no extra 
activities in destination station, the paper deduced the unique train chosen in the OD pair by the exit time. Then, the route was deduced until the origin station. The result of this model was more accurate and realistic, confirming the train number and stations passed in each OD pair. But, the algorithm was too complicated even in computer technology. In addition, the assumption of no extra activities needed to be improved.

In emergent circumstance, the accurate result and simple algorithm of the model were both important. Too complicated algorithm was not suitable for the quick response of emergent decision. Several researches were focused on emergent condition while most of them dedicated to politics and emergent strategies. And few papers were concerned with passenger flow assignment.

Hong [9] divided emergent passenger flow into three parts: delay passenger flow, detour passenger flow, and loss passenger flow. With graph theory, the paper built evaluation models for all kinds of influenced passenger flow in every impacted station using historical OD matrix in URT network. In addition, with those models, influenced, detour, congested, and loss passenger flow volume with lost time of passenger flow could be calculated out in different stations as time went by. However, the shortest path was only the considered route in route choice set of incidence matrix, which meant that no additional choice routes were provided for passengers and the passenger's behaviors were not considered. In addition, the impacted passenger flow volume calculated in this paper was separated by every station and the flow had no direction. Furthermore, a detailed shuttle bus plan was hardly made in recovery phase by the results.

Pan [10] established a dynamic assignment model of the passenger flow in emergency. The paper analyzed the structure and characteristics of emergent passenger flow and URT network. Although passengers' features were discussed, they were not used in the assignment model. In addition, the basic data, the OD matrix, was not analyzed. Therefore, some key links about passengers' behavior and choice were not sufficiently studied. Liu [11] made the plans of shuttle bus in two conditions, sufficient resource and insufficient resource, which were based on the number of shuttle buses. And, a modified logit model was developed for passenger flow assignment. However, this paper failed to show the results of SP survey and the support to modified logit model was insufficient.

In summary, passenger flow assignment on normality in URT network was studied extensively, and several researches explored the emergent circumstance. But they were still on preliminary stages, and more attention needs to be paid to the passenger behavior and preference.

\section{Methodology}

\subsection{Stated Preference Survey}

SP survey is to achieve the subjective preference of the respondents in different assuming conditions. SP survey originates from economics, as a market research tool to understand the consumers' acceptance to different products or service [12]. In the late 1970s, SP survey was introduced to analyze the traffic issues in UK. Until 1983, SP survey was first used in traffic mode choice of citizens by Louviere and Hensher [13]. Nowadays, SP survey has been applied in the study of travel mode choice, parking choice, route choice, etc. [14].

Overall design is used in this scene design, and to combine all the levels of every variable. For example, a study has $\mathrm{m}$ factors and every factor has $\mathrm{n}$ levels. The total number of scenes is $\mathrm{n}^{\mathrm{m}}$. This approach is able to acquire the comprehensive information and the conclusion is relative accuracy.

\subsection{Multinomial Logit Model}

Generally, if passenger's perceived travel cost is represented as a random variable consisting of a deterministic component $C_{k}^{\mathrm{rs}}$ and an additive random error. Accordingly, passenger's path choice is actually a probability. The probability of a given path chosen by a passenger can be defined by calculating the probability that the perceived travel cost on such path is lower than that of all other alternatives. Obviously, the choice probability is determined by both of the distribution of random error term and the expected travel cost $C_{k}^{\text {rs }}$ [6]. The multinomial logit model is as the following:

$P_{k}^{\mathrm{rs}}=\frac{\exp \left(-\theta C_{k}^{\mathrm{rs}}\right)}{\sum_{m} \exp \left(-\theta C_{m}^{\mathrm{rs}}\right)}, k \in K_{\mathrm{rs}}$,

where $P_{k}^{\text {rs }}$ is the choice probability of effective path $k(k \in$ $K_{\mathrm{rs}}$ ) between the OD pair r-s; $\theta$ is the dispersion parameter, which is inversely proportional to the standard error of the distribution of the perceived path travel cost [15].

\section{Data Preparation}

Two surveys were made for this paper: a passenger behavior survey and a SP survey. The passenger behavior survey, as a pre-survey, provided some important basis to the SP survey such as the expected speed and crowding degree of the shuttle bus. The estimation result of models was determined by the SP survey. 


\subsection{Passenger Behavior Survey}

The target of this survey was to understand the demand characteristics of the passenger flow in URT emergency.

The survey sample includes 266 men, accounting for $53.2 \%$ of the total (500), and 234 women, accounting for $46.8 \%$. In addition, $92.4 \%$ of people surveyed are young (under $30,43.8 \%$ ) or middle-aged $(30-60,48.6 \%$ ), respectively, whereas $7.6 \%$ are seniors (above 60 ). As long as occupation is concerned, there are officials, businessmen, students, temporary employments, etc. These samples are representative and can be used in the study of the demand features of the passenger flow in URT emergency.

Figure 1a shows that $58 \%$ of respondents use URT every day and $88 \%$ of subjects use it at least three times a week. It indicates URT plays a non-substitutable role in citizens' daily life. Figure $1 \mathrm{~b}$ shows the main purpose is commute $(32 \%)$ which is the rigid demand. In addition, most of business $(15 \%)$ and journey $(11 \%)$ are hardly to be adjusted to other modes as well as some of family visit $(10 \%)$, entertainment (11\%), and shopping (17\%). That means as URT emergent events happen, it will have a huge impact.

Figure 2a shows $87 \%$ respondents consider the bus, either the temporary shuttle buses (54\%) or the existed bus lines nearby (33\%), should give support to URT to carry passengers before URT restores to normal service. The ratio of acceptable travel time by shuttle bus over the travel time by URT is shown in Fig. 2b. The percentages of less than two times and 1.5 times are 88 and $64 \%$. The average travel speed of URT is 3-4 times higher than the bus [16]. Therefore, it is quite challenging to satisfy it.

Figure $2 \mathrm{c}-\mathrm{d}$ focuses on other two key factors: waiting time and crowding degree. $57 \%$ respondents expect that the acceptable waiting time of the shuttle bus is 10-20 min. And $20 \%$ expect less than $10 \mathrm{~min}$. Although the average waiting time of the key bus line is $5 \mathrm{~min}$ in peak hour [16], it is hard to reach the expectancy under emergent circumstance. Figure $2 \mathrm{~d}$ describes that some people surveyed (13\%) pay attention to available seats, but most respondents $(75 \%)$ just care for the available standing and activity space.

The survey results present in Fig. 2 provide empirical evidence for understanding which is the best alternative traffic mode of passengers' expectation. Moreover, the crowding degree is considered along with the speed of shuttle bus and URT. It provides important guidance on how to set crowding degree and relative speed in SP survey. In addition, the acceptable waiting time of the shuttle bus offers support to shuttle bus organization.

\subsection{Stated Preference Survey}

A SP survey was prepared for model calibration. This survey was divided into three parts: travel characteristics, scene selection, and personal attributes.

Travel characteristics included travel purpose, type of the luggage, origin station, and destination station.

Scene selection was retrieved by the crowding degree in the shuttle bus and relative speed. This survey provided two levels of in-vehicle congestion and three levels of relative speed. According to passenger behavior survey, the paper assumed the crowding degree in URT was crowded and two levels of crowding in the shuttle bus were set: abundant standing space and crowed. In addition, as the average travel speed of URT is 3-4 times higher than the bus and $88 \%$ of the respondents in passenger behavior survey expect the relative speed is $1 / 2$ or more of the URT,
Fig. 1 Frequency and purpose of using URT system trip frequency

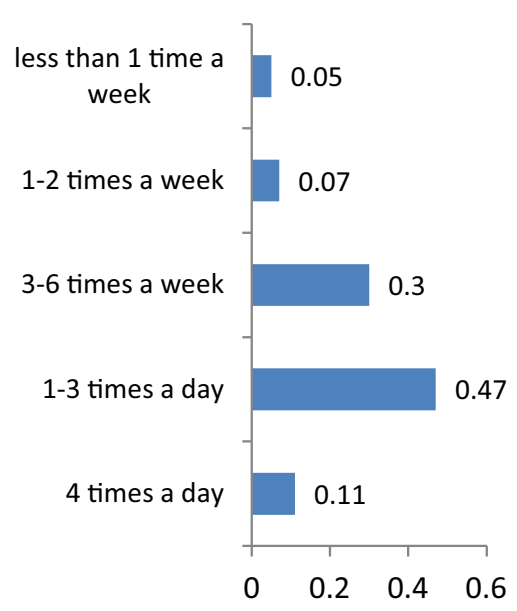

(a) trip purpose

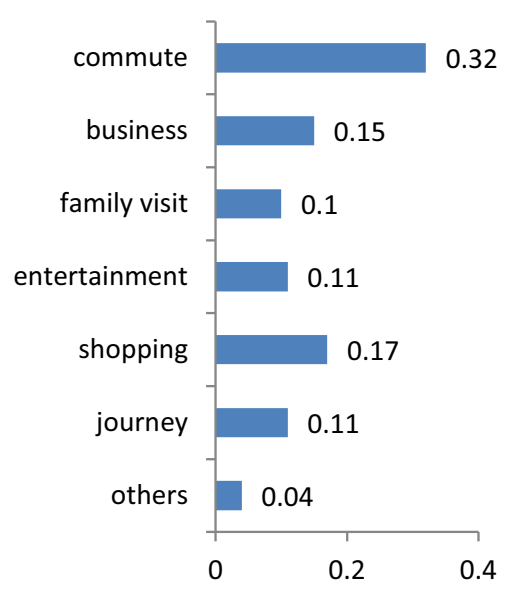

(b) 
Fig. 2 Traffic option in URT emergent events

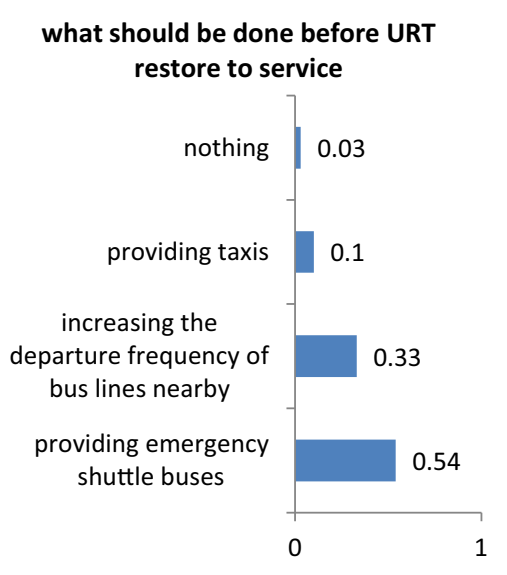

(a)

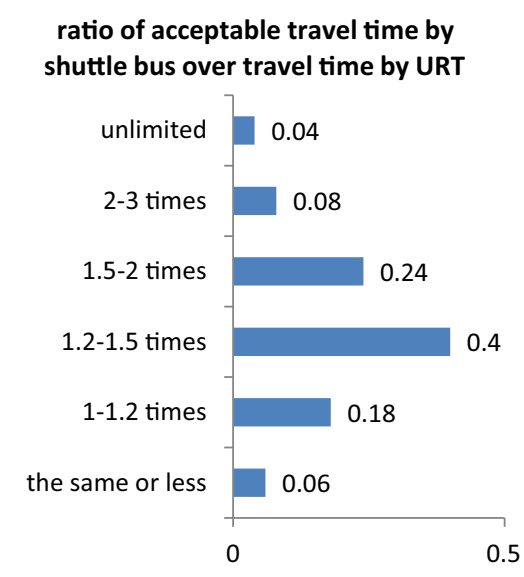

(b)

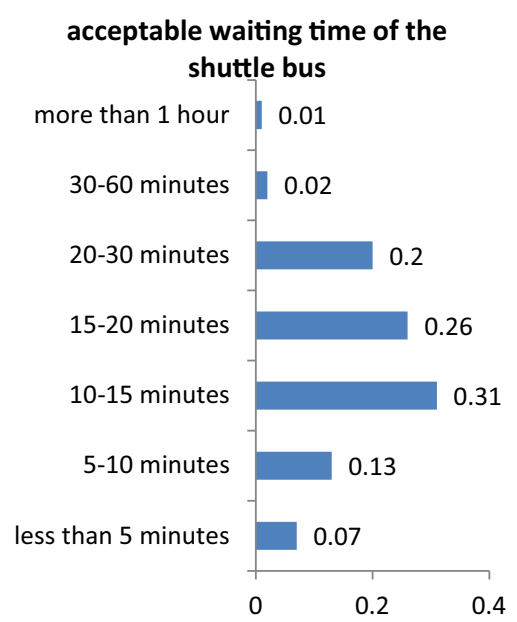

(c)

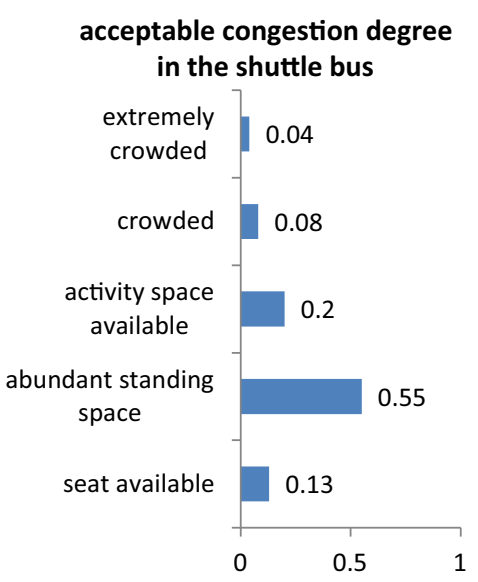

(d) three levels of relative speed were set: 1/2, 1/4, 1/6. The combination of crowding degree and relative speed differs among scenes. Totally, six scenes are provided.

Personal attributes included passenger's gender, age, and income per month. Figure 3 shows the part of Shanghai Metro system.

Meanwhile, the paper supposed the section from Shanghai Railway station to People Square Station of Metro Line 1 was interrupted, as shown in Fig. 3. Then the URT would run on two part routes [17]: (1) departing from Fujin Road to Shanghai Railway Station and then back to Fujin Road; (2) departing from Xinzhuang to People Square and then back to Xinzhuang. The survey stations were selected from North Zhongshan Road to Gongkang Road, including six stations. Moreover, the only direction concerned in this survey was from Fujin Road to Xinzhuang.

Totally, 300 passengers were surveyed, 50 in each survey station, and 545 effective records were collected. The core of this survey is about the preference of passengers' route choice. The participants were asked to make a selection in a set of four pre-defined traffic modes which decided the travel path. These alternative traffic modes and the corresponding ODs are used to study passengers' tradeoff between relative speed and crowding degree. The information provided includes the location of interrupting section, crowding degree in the shuttle bus, and relative speed along these traffic modes. Four choices were prepared and described as

- A circuitous way to the destination station by URT; (mode 1: metro)

- Traveling from Shanghai Railway Station to a certain station by the shuttle bus, then transferring to URT and finishing the trip; (mode 2: metrobus1)

- Traveling from Shanghai Railway Station to the destination station by the shuttle bus; (mode 3: metrobus2)

- Using other traffic modes, such as taxi. (mode 4: Other) 


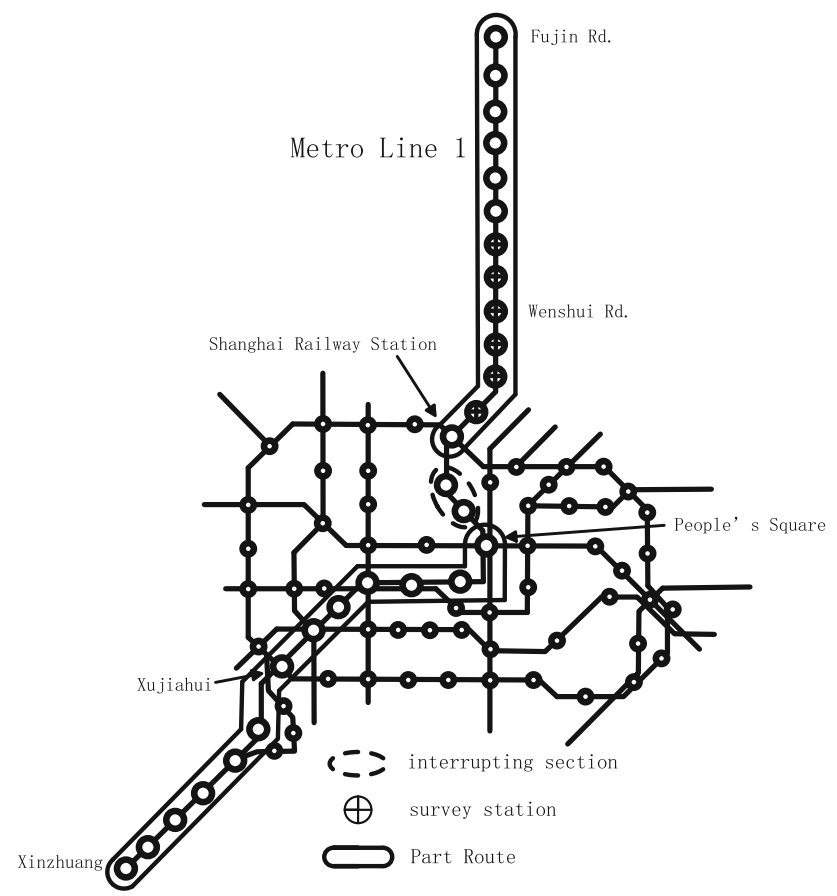

Fig. 3 Location of interrupting section and the organization of part routes

Figure 4 shows the proportion of the different passengers (classified by age, gender, and income) and the different trip purposes among these four alternative modes. It can be seen that, the proportions of passengers choosing mode 1 are consistently the highest, followed by mode 4 , mode 3 , and mode 2 across all passengers and trip purposes. In addition, in most cases, more passengers prefer mode 3 than mode 2, indicating that they would like to trade the one mode way with less transfer between different traffic modes. The choice proportions vary at a high level in Fig. $4 \mathrm{a}$ and c. The passengers over 60 years old show high interests in mode 1 for the following two possible reasons: (1) senior passengers travel free of charge by public transit; (2) a more complicated way and an unfamiliar transfer place may be a big challenge to the seniors. In Fig. 4c, it is reasonable to understand highincome groups prefer mode 4 , such as taxi, than the URT and the shuttle bus.

Meanwhile, Fig. 4e shows the crowding degree getting heavy in the shuttle bus, the passengers will abandon mode 2 and mode 3 , choosing mode 1 and mode 4 . However, the percentage of each choice varies slightly. That is the passenger choice is affected by the crowding degree in the shuttle bus but it is not the key one, in the emergent circumstance. Figure $4 \mathrm{f}$ shows that as the shuttle bus speed slows down, the percentage of mode 1 rises. Moreover, the percentages of mode 2 and 3 drop rapidly when the relative speed changes from $1 / 4$ to $1 / 6$. As said in scene selection, $1 / 4$ is the relative speed in normal state. It means that the passengers cannot bear that the shuttle bus speed is slower than the normal speed.

Another important point needs to be focused. Almost $8.4 \%$ of the total effective records choose mode 2 . All of the "certain stations" are transfer stations with People Square selected by $75.6 \%$, followed by East Nanjing Rd., Xujiahui, Changshu Rd., Jiangsu Rd., etc. So, the destination of mode 2 can be narrowed down in the transfer stations and the station of maximum demand is at the first transfer station after the interrupting section.

The surveys' results in Figs. 1, 2, and 4 provide empirical evidence for understanding which factors are included and how they are traded off among each other, when passengers calculate a "utility" for each potential traffic mode, rank them, and make their final choices. Such results present important guidance on how the utility functions and corresponding logit models for traffic mode choices should be constructed. These models are introduced in the following section.

\section{Estimation Results}

\subsection{Variable}

According to the conducted survey, the passengers' route choice is influenced by crowding degree in the shuttle bus and relative speed. Other travel characteristics and personal attributes are also considered in the choice model. They are gender, age, income, luggage, purpose, SDB (relative speed), and YJD (the crowding degree in the shuttle bus). Furthermore, several additional travel characteristics are prepared for the choice model based on the OD information. They are

- MRSQ:

\footnotetext{
MRSQ $=\frac{\text { The number of stations from destination station to People Square }}{\text { The number of stations from origin station to Shanghai Railway Station }}$
} 
- SRZB:

SRZB $=\frac{\text { The number of stations in shortest route after interruption occurence }}{\text { The number of stations in shortest route before interruption occurence }}$

- HCSC:

HCSC $=$ Transfer times in shortest route after interruption occurrence - transfer times in shortest route before interruption occurrence

- COST: the meaning of this factor varies in every alternative choice. (1) The pricing method of Shanghai URT system is restricted by the origin and destination stations information, without regarding which stations the route passed. That is, the cost in emergency is the same as in normal state. (2) As the shuttle bus replaces the interrupting section, passengers must leave and reenter the URT system. The cost consists of four parts: (a) origin station to Shanghai Railway Station; (b) Shanghai Railway Station to a certain subway station by the shuttle bus. This service is free based on the previous emergent situations. (c) A certain station to destination station. (d) ¥1 privilege is given at reentering the URT system. (3) The only cost passengers need to pay is from origin station to Shanghai Railway Station. (4) Taxi fare is used as the cost of mode 4.

\subsection{Utility Function}

\subsubsection{Initial Utility Function}

The paper sets mode 4 as the base case. And the utility functions are described as follows:

$$
\begin{aligned}
& U(\text { metro })=a_{1}+b_{11} \times \text { gender }+b_{12} \times \text { age } \\
& \quad+b_{13} \times \text { income }+b_{14} \times \text { luggage }+b_{151} \times \text { purpose } 1 \\
& \quad+b_{152} \times \text { purpose } 2+b_{153} \times \text { purpose } 3 \\
& \quad+b_{154} \times \text { purpose } 4+b_{155} \times \text { purpose } 5+b_{16} \times \text { mrsq } \\
& +b_{17} \times \text { srzb }+b_{18} \times \text { hcsc }+b_{19} \times \mathrm{sdb}+b_{1} \times \text { cost }+\varepsilon_{1} ; \\
& U(\text { metrobus } 1)=a_{2}+b_{21} \times \text { gender }+b_{22} \times \text { age } \\
& \quad+b_{23} \times \text { income }+b_{24} \times \text { luggage }+b_{251} \times \text { purpose } 1 \\
& \quad+b_{252} \times \text { purpose } 2+b_{253} \times \text { purpose } 3 \\
& \quad+b_{254} \times \text { purpose } 4+b_{255} \times \text { purpose } 5+b_{26} \times \mathrm{sdb} \\
& \quad+b_{27} \times \mathrm{yjd}+b_{1} \times \text { cost }+\varepsilon_{2} ;
\end{aligned}
$$

$$
\begin{aligned}
& U(\text { metrobus } 2)=a_{3}+b_{31} \times \text { gender }+b_{32} \times \text { age } \\
& \quad+b_{33} \times \text { income }+b_{34} \times \text { luggage }+b_{351} \times \text { purpose } 1 \\
& \quad+b_{352} \times \text { purpose } 2+b_{353} \times \text { purpose } 3 \\
& \quad+b_{354} \times \text { purpose } 4+b_{355} \times \text { purpose } 5 \\
& \quad+b_{36} \times \mathrm{sdb}+b_{37} \times \mathrm{yjd}+b_{1} \times \operatorname{cost}+\varepsilon_{3} ; \\
& U(\text { other })=b_{1} \times \text { cost }+\varepsilon_{4},
\end{aligned}
$$

where gender- 0 , male; 1 , female;

Income—0, below $¥ 2500$ /month; 1, ¥2500- $¥ 4000$ / month; 2, ¥4001-¥7000/month; 3, ¥7001-¥10,000/month; 4 , beyond $¥ 10,000 /$ month;

Luggage -0 , no luggage; 1 , a briefcase; 2 , a trunk; 3 , two suitcases or more;

Purpose 1 to 5-commute, business, visit, shopping, other; $\mathrm{Sdb}$-relative speed;

Yjd-the crowding degree in the shuttle bus.

\subsubsection{Significance Testing and Modified Utility Function}

Significance tests were conducted for all factors and a factor is considered significant $P$ value $<0.1$. Some results of significance tests are shown in Table 1 .

There are two points that need to be emphasized. (1) The factors, purpose2 (business), purpose 4 (shopping), and purpose5 (other), are all insignificant in utility functions of $\mathrm{U}$ (metro), $\mathrm{U}$ (metrobus1), and $\mathrm{U}$ (metrobus2). These factors will be abandoned from the choice model. (2) SDB and YJD are also insignificant in utility functions. However the six scenes, the organization of the shuttle bus and the basic support in emergency are all decided by these two factors. So, SDB and YJD will be reserved.

The modified utility functions are shown as follows:

$$
\begin{aligned}
& U(\text { metro })=a_{1}+b_{11} \times \text { gender }+b_{12} \times \text { age } \\
& \quad+b_{13} \times \text { income }+b_{14} \times \text { luggage }+b_{151} \times \text { purpose } 1 \\
& \quad+b_{153} \times \text { purpose } 3+b_{16} \times \text { mrsq }+b_{17} \times \text { srzb } \\
& \quad+b_{18} \times \text { hcsc }+b_{19} \times \mathrm{sdb}+b_{1} \times \text { cost }+\varepsilon_{1} ; \\
& U(\text { metrobus } 1)=\mathrm{a}_{2}+\mathrm{b}_{21} \times \text { gender }+\mathrm{b}_{22} \times \text { age } \\
& \quad+\mathrm{b}_{23} \times \text { income }+\mathrm{b}_{24} \times \text { luggage }+\mathrm{b}_{251} \times \text { purpose } 1 \\
& \quad+\mathrm{b}_{253} \times \text { purpose } 3+\mathrm{b}_{26} \times \mathrm{sdb}+\mathrm{b}_{27} \times \text { yjd } \\
& \quad+\mathrm{b}_{1} \times \text { cost }+\varepsilon_{2} ;
\end{aligned}
$$




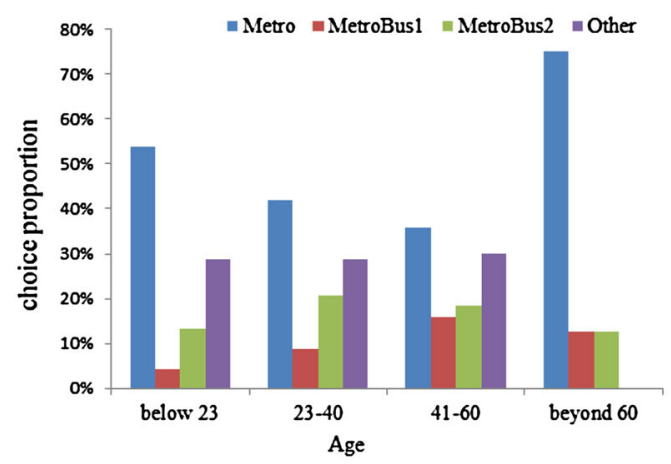

(a) Age

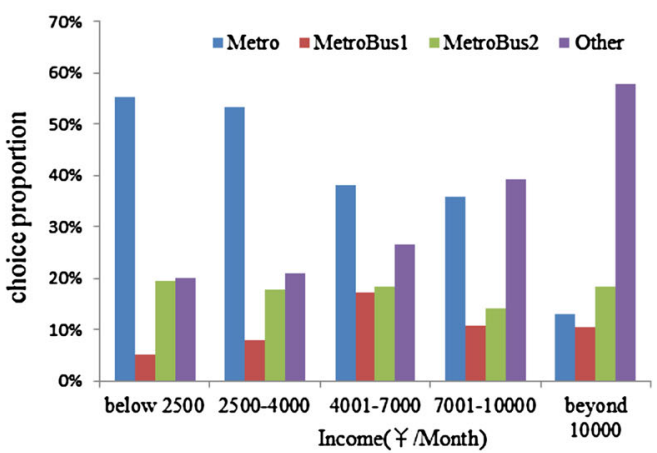

(c) Income

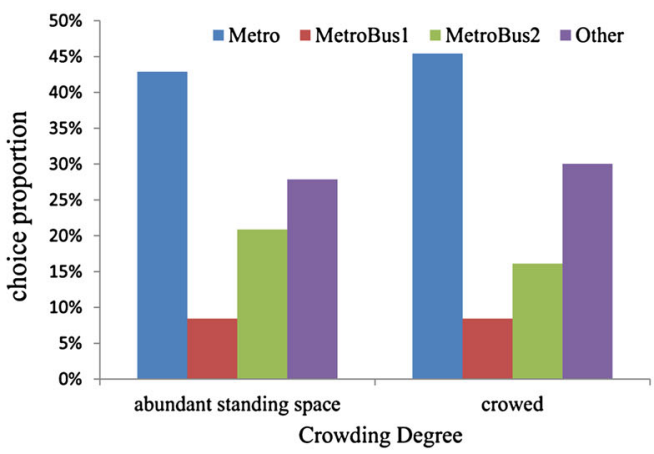

(e) Crowding Degree

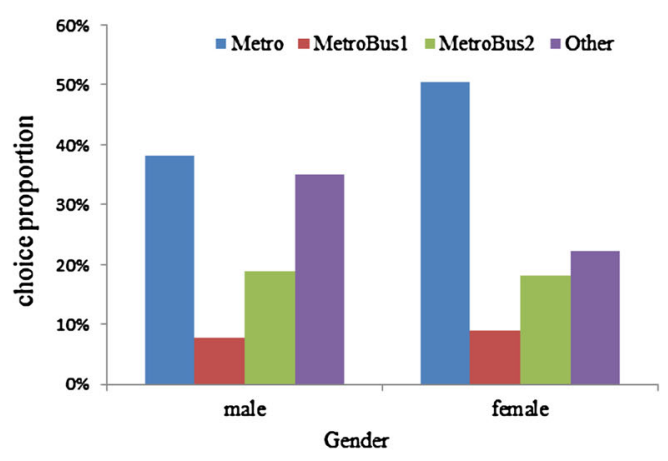

(b) Gender

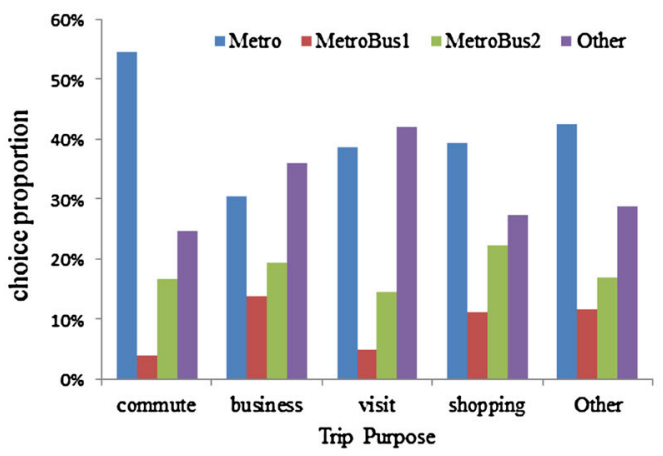

(d) Trip Purpose

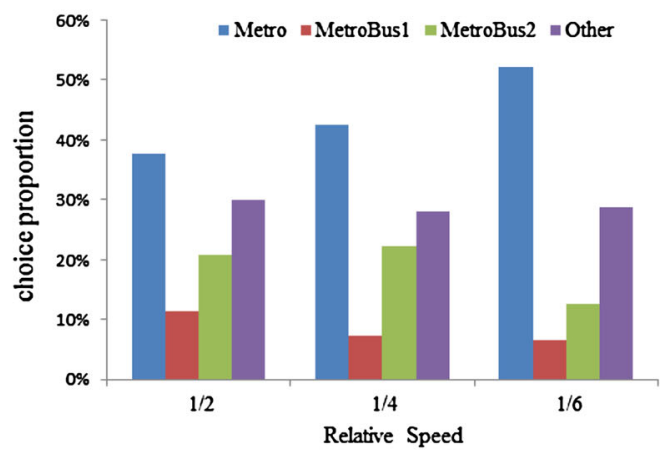

(f) Relative Speed

Fig. 4 Analysis of traffic mode choice

$$
\begin{aligned}
& U(\text { metrobus } 2)=a_{3}+b_{31} \times \text { gender }+b_{32} \times \text { age } \\
& \quad+b_{33} \times \text { income }+b_{34} \times \text { luggage }+b_{351} \times \text { purpose } 1 \\
& \quad+b_{353} \times \text { purpose } 3+b_{36} \times \text { sdb }+b_{37} \times \text { yjd } \\
& \quad+b_{1} \times \text { cost }+\varepsilon_{3} ; \\
& U(\text { other })=b_{1} \times \cos t+\varepsilon_{4} .
\end{aligned}
$$

\subsubsection{Fitting Result}

The fitting results for the choice model are shown in Table 2.

The fitted utility functions are shown as follows:

$$
\begin{aligned}
& U(\text { metro })=2.1716+0.5972 \times \text { gender }+0.0238 \times \text { age } \\
& \quad-0.4897 \times \text { income }-0.1862 \times \text { luggage } \\
& \quad+0.3271 \times \text { purpose } 1-0.6257 \times \text { purpose } 3 \\
& \quad+0.0161 \times \text { mrsq }-1.0162 \times \text { srzb }-0.0542 \times \text { hcsc } \\
& \quad-1.2603 \times \text { sdb }-0.0073 \times \text { cost }+\varepsilon_{1} ; \\
& U(\text { metrobus } 1)=-4.6176+0.5136 \times \text { gender } \\
& \quad+0.0434 \times \text { age }-0.1450 \times \text { income } \\
& \quad-1.0391 \times \text { luggage }-0.9707 \times \text { purpose } 1 \\
& \quad-1.5144 \times \text { purpose } 3+1.5529 \times \text { sdb }-0.1201 \times \text { yjd } \\
& \quad-0.0073 \times \text { cost }+\varepsilon_{2} ;
\end{aligned}
$$


Table 1 Some results of significance testing

\begin{tabular}{llllll}
\hline Factor & & $P$ value & Factor & & $P$ value \\
\hline Purpose2 & $b_{152}$ & 0.1460 & Purpose 4 & $b_{154}$ & 0.6668 \\
& $b_{252}$ & 0.5795 & & $b_{254}$ & 0.1179 \\
& $b_{352}$ & 0.7032 & & $b_{354}$ & 0.1565 \\
Purpose5 & $b_{155}$ & 0.9416 & SDB & $b_{19}$ & 0.1736 \\
& $b_{255}$ & 0.2977 & & $b_{26}$ & 0.1701 \\
& $b_{355}$ & 0.7925 & & $b_{36}$ & 0.3836 \\
YJD & $b_{27}$ & 0.8204 & & & \\
& $b_{37}$ & 0.1420 & & & \\
\hline
\end{tabular}

$$
U(\text { metrobus } 2)=-0.2216+0.3566 \times \text { gender }
$$$$
+0.0171 \times \text { age }-0.3206 \times \text { income }
$$$$
-0.1156 \times \text { luggage }-0.0976 \times \text { purpose } 1
$$$$
-0.7086 \times \text { purpose } 3+0.7228 \times \mathrm{sdb}-0.3724 \times \text { yjd }
$$$$
-0.0037 \times \operatorname{cost}+\varepsilon_{3} \text {; }
$$

$U($ other $)=-0.0073 \times \operatorname{cost}+\varepsilon_{4}$.

Some signs of coefficients in the estimated multinomial logit model have important meaning and can give basic support to decision makers. The coefficients of gender in the three utility functions are $0.5972,0.5136$, and 0.3566 . Compared with female, male prefers changing the malfunctioning URT system to a new traffic mode. Especially, male shows less interest in mode 1 . Well, female seems more conservative and would like to continue in the former mode. The signs of income in utility functions are negative. As income increases, people are partial to abandon the URT to the other traffic modes, such as taxi. The coefficients of luggage in three utility functions are $-0.1862,-1.0391$, and -0.1156 . Public transit possibly leaves a crowded and unsafe impression to passengers, so other traffic modes are more attractive in the URT emergency to the passengers with luggage. Moreover, the passengers with luggage mostly give up $U$ (metrobus1) first because the transfer between the URT and the shuttle bus is tough.

Based on the sign of MRSQ (+), the higher the percentage of distance left in the trip, the more interest passengers show to the mode of metro. As for SRZB (-), the longer the detouring distance is, the low percentage of mode 1 passengers will choose. The HCSC (-) means the transfer times in URT show a negative effect to $U$ (metro).

The factors of SDB and YJD both state passengers would show more interests to the shuttle bus by higher relative speed and lower crowding. Meanwhile, the SDB is more important in metrobus1 than metrobus2 for $b_{26}(1.5529)>b_{36}(0.7228)$. The demand of YJD in mode 3 is much more vital than in mode 2 because the distance in bus in mode 3 is mostly longer than mode 2 .
Table 2 Estimation results of the choice model

\begin{tabular}{|c|c|c|c|}
\hline Variables & Coef. & S.E. & $P$ value \\
\hline Cost & -0.0073 & 0.0038 & 0.0539 \\
\hline \multicolumn{4}{|l|}{$\mathrm{U}($ metro) } \\
\hline Constant & 2.1716 & 0.8285 & 0.0088 \\
\hline Gender & 0.5972 & 0.2349 & 0.0110 \\
\hline Age & 0.0238 & 0.0115 & 0.0380 \\
\hline Income & -0.4897 & 0.1011 & 0.0000 \\
\hline Luggage & -0.1862 & 0.2221 & 0.4017 \\
\hline Purpose1 & 0.3271 & 0.2530 & 0.1961 \\
\hline Purpose 3 & -0.6257 & 0.3651 & 0.0865 \\
\hline MRSQ & 0.0161 & 0.0558 & 0.7729 \\
\hline SRZB & -1.0162 & 0.5365 & 0.0582 \\
\hline HCSC & -0.0542 & 0.1392 & 0.6969 \\
\hline SDB & -1.2603 & 0.8063 & 0.1180 \\
\hline \multicolumn{4}{|c|}{$\mathrm{U}($ metrobus 1$)$} \\
\hline Constant & -4.6176 & 1.0925 & 0.0000 \\
\hline Gender & 0.5136 & 0.3636 & 0.1577 \\
\hline Age & 0.0434 & 0.0159 & 0.0063 \\
\hline Income & -0.1450 & 0.1542 & 0.3472 \\
\hline Luggage & -1.0391 & 0.3511 & 0.0031 \\
\hline Purpose1 & -0.9707 & 0.4680 & 0.0381 \\
\hline Purpose 3 & -1.5144 & 0.6723 & 0.0243 \\
\hline SDB & 1.5529 & 1.2109 & 0.1997 \\
\hline YJD & -0.1201 & 0.3256 & 0.7122 \\
\hline \multicolumn{4}{|c|}{ U(metrobus2) } \\
\hline Constant & -0.2216 & 0.7430 & 0.7655 \\
\hline Gender & 0.3566 & 0.2793 & 0.2017 \\
\hline Age & 0.0171 & 0.0136 & 0.2093 \\
\hline Income & -0.3206 & 0.1175 & 0.0064 \\
\hline Luggage & -0.1156 & 0.2615 & 0.6585 \\
\hline Purpose1 & -0.0976 & 0.3071 & 0.7507 \\
\hline Purpose 3 & -0.7086 & 0.4513 & 0.1164 \\
\hline SDB & 0.7228 & 0.9211 & 0.4326 \\
\hline YJD & -0.3724 & 0.2299 & 0.1053 \\
\hline
\end{tabular}

Summary statistics

Number of observations $\quad 546$

Log likelihood function $\quad-608.2048$

$R^{2} \quad 0.0782$

Most variables are significant $(P$ value $<0.1)$ enough. They are gender, age, income, purpose3, SRZB, cost, luggage, and purpose1. The most significant $(P$ value $<0.01)$ variables are income $(P$ value $=0.0000$ in mode 1 and 0.0064 in mode 3$)$, age ( $P$ value $=0.0063$ in mode 2$)$, and luggage ( $P$ value $=0.0031$ in mode 2$)$. Some necessary measures need to be paid attention to are (a) Abundant subway staffs need to be prepared in emergency to help the seniors and the temporary passages must be easy to use. (b) A special aisle and some big volume of security check machines need to be provided for 
Table 3 Values of variables

\begin{tabular}{lllllll}
\hline Variable & Gender & Age & Income & Luggage & Purpose1 & Purpose3 \\
Value & 0 & 30 & 2 & 0 & 1 & 0 \\
Variable & MRSQ & SRZB & HCSC & Cost in mode 1 & \\
Value & 1.25 & 0.9167 & 2 & 4 & Cost in mode 4 \\
Variable & Cost in mode 2 & Cost in mode 3 & 47 \\
Value & 6 & & 3 & & 47 \\
\hline
\end{tabular}

Fig. 5 Impacts of SDB values on computed results
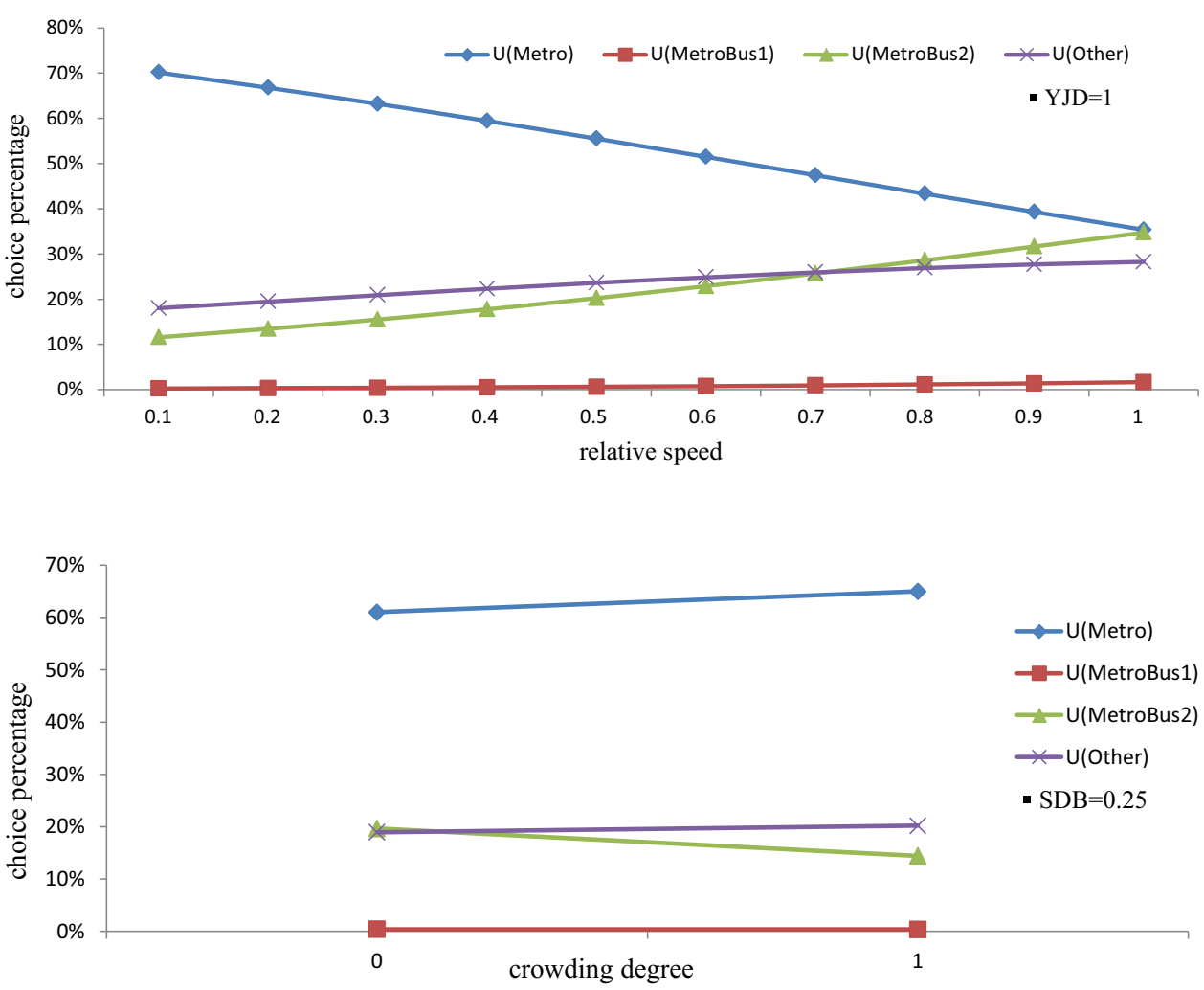

Fig. 6 Impacts of YJD values on computed results passengers with luggage. Another key variable for the model is cost (Coef. $=-0.0073 ; P$ value $=0.0539)$. Obviously, cost makes a negative effect in the choice model. As the cost of mode 2 is not cheaper than mode 3 in every OD pair, it directly leads that the choice percentage of mode 2 is lower than mode 3 . To decrease the pressure on the shuttle, the decision makers can cut down the cost in mode 2 or increase the cost in mode 3 . For example, free service can be provided after reentering the URT system or a whole journey ticket can be offered in mode 2 . And in mode 3 , it is suitable to increase the cost of the long distance journey by the shuttle bus.

\subsubsection{Sensitivity Analysis}

A further analysis is prepared for SDB and YJD in the proposed model. An OD pair from Wenshui Road to
Xujiahui is selected, shown in Fig. 3. The given values of other variables are shown in Table 3.

Sensitivity of Computational Results with Relative Speed assuming the shuttle bus is crowded (YJD = 1), SDB values change from $1 / 10$ to 1 and assignment results are calculated. Figure 5 shows the assignment results when SDB takes different values. It can be seen that the changes of SDB within a certain scope influence mode 1 and mode 3 strongly. But, with SBD increasing, the choice percentage changes regularly. If SDB is very large, passengers will tend to select the path in which the shuttle bus is used to the maximum (mode 3). In addition, the specific passenger group results in the low percentage of mode 2 which is the same with next part (2)).

Sensitivity of Computational Results with Crowding Degree assuming the relative speed is $0.25(\mathrm{SDB}=0.25)$, the YJD values are limited to 0 and 1. Figure 6 compares the choice percentage with different YJD values used. 
It can be seen that the changes of YJD only have very minor impacts on the assignment results. This can be explained as the follows: as the value of YJD increases, the assignment results of traffic modes, including the shuttle bus, decrease but slightly (mode 2, 0.39-0.37 \%; mode 3, $19.65-14.44 \%)$. That means the crowding degree is not the key factor influencing the passengers' choice in emergent circumstance. Passengers may show more interests in the accessibility of the traffic modes. Decision makers can pay less attention to the comfort in the shuttle bus.

\section{Conclusion}

The assignment of passenger flow is the basic support to emergent organization in the section interruption of the URT system. The literature summaries two types of methods for passenger flow assignment: equilibrium assignment model and utility theory based non-equilibrium assignment model. As the choice result is high correlation to passenger behavior in emergent situation, the latter one is chosen in this paper because more passengers' behavior features can be included in it. Two surveys (a passenger behavior survey and a SP survey) were made and a multinomial logit model was developed in this research.

The passenger behavior survey contains trip features and passenger preference in emergency. More than half of the respondents show interests in the shuttle bus. The relative speed ranging from $1 / 2$ to $2 / 3$ is suitable to the passengers' demand. But, it is quite challenging to satisfy it. Moreover, most respondents $(75 \%)$ just care for the available standing and activity space in the shuttle bus and the crowding degree shows slight impact on the passenger choice in the model. Some support in organization is provided by passengers' other preference.

The SP survey presents that the first choice of passengers in emergency is to stay in the URT system by circuitous ways if they exist. A further analysis of variables was made in the choice model. Comparing relative speed and crowding degree, the former is more important to the passenger choice judging by the sensitivity analysis. This result is the same with the passenger behavior survey. The impacts of trip feature factors are similar compared to the previous research in normal state (6) (7), such as HCSC and SRZB. The significant variables mostly fall in the personal attribute. They are income, gender, age, etc. This indicates that the equilibrium assignment model, seldom including the personal attribute and behavior, is not suitable for this situation. Meanwhile, the results of the choice model can assist urban traffic management department to build the scheduling scheme of the shuttle bus. It also can satisfy passengers' travel demand in section interruption circumstance and reduce the risk of crowding at some special stations.
Future research will focus on two aspects. One is to test the model in actual environment. But since section interruption seldom happens in Shanghai URT system, it is hard to complete the empirical work. So, the best practicable way is to expand the sample size. The other one is to build the scheduling scheme of the shuttle bus because the passenger choice will be influenced by the scheduling scheme.

Acknowledgments This research was supported by the Construction Project of Transportation Science and Technology, Ministry of Transport of the People's Republic of China, (Research on the technologies for initiatively preventing and controlling the safety risk of urban passenger network, Grant No. 2015318221020), and the Key Laboratory of Road and Traffic Engineering of the Ministry of Education, Tongji University.

Open Access This article is distributed under the terms of the Creative Commons Attribution 4.0 International License (http://crea tivecommons.org/licenses/by/4.0/), which permits unrestricted use, distribution, and reproduction in any medium, provided you give appropriate credit to the original author(s) and the source, provide a link to the Creative Commons license, and indicate if changes were made.

\section{References}

1. Transportation Research Board (2007) Transit Cooperative Research Program (TCRP) Report 86. Public Transport Security

2. European Commission Directorate-General for Energy and Transport (2004) Towards passenger intermodality in the EU

3. Shanghai Municipal Transportation Commission (2011) Disposal of Shanghai urban rail transit in emergency (in Chinese)

4. Beijing Municipal Transportation Commission (2007) Disposal of Beijing urban rail transit in emergency (in Chinese)

5. Zhu W, Hu H (2013) Modified stochastic user-equilibrium assignment algorithm for urban rail transit under network operation. J Center South Univ 20:2897-2904

6. Si, BF, Zhong, M (2013) Development of a transfer-cost based passenger flow assignment model for Beijing rail transit network using automated fare collection data. Presented at 92nd annual meeting of the Transportation Research Board, Washington, D.C.

7. Si BF, Zhong M (2013) Development of a transfer-cost-based logit assignment model for the Beijing rail transit network using automated fare collection data. J Adv Transp 3(47):297-318

8. Zhou F, Xu RH (2012) Passenger flow assignment model for urban rail transit based on entry and exit time constraints. Transp Res Rec 2284:57-61

9. Hong L, Gao J (2011) Calculation method of emergency passenger flow in urban rail network. J Tongji Univ (Nat Sci) 10(39):1485-1489 in Chinese

10. Pan HC, Sun YS (2011) Dynamic assignment of emergency passenger flows after metro accidents. In: Proceedings of the 3rd international conference on transportation engineering. Chengdu, China

11. Liu WR, Teng J (2014) Organization of a the shuttle bus under the condition of operation interruption to urban rail transit. In: Proceedings of the 14th COTA international conference of transportation professionals. Changsha, China

12. Zhao SZ, Zhao B (2009) Choice model of trip mode and policy of public transport priority based on SP survey. J Jilin Univ (Eng Technol Ed) 39(2):187-190 (in Chinese) 
13. Wang F, Chen JC (2005) Uniformity design method for SP survey in transportation. Urban Transp China 13(3):69-72 (in Chinese)

14. Hu YC, Xu JM (2001) Application of SP survey method in car ownership study. J Highw Transp Res Dev 18(2):86-89 (in Chinese)

15. Sheffi Y (1985) Urban transportation networks: equilibrium analysis with mathematical programming methods. Prentice-Hall, Englewood Cliffs
16. Ma CQ, Wang YP (2007) Competition model between urban rail and bus transit. J Transp Syst Eng Inf Technol 7(3):140-143

17. Shanghai Shentong Metro Group Corporation (2005) The prearranged plan in emergent events (in Chinese) 